\title{
Investigation of Fluid Flow Velocity Within the Lumbar Intervertebral Disc
}

\author{
Sandra MIKUCKYTE்*, Vytautas OSTAŠEVIČIUS** \\ *Kaunas University of Technology, Studentu str. 56, 51424, Kaunas, Lithuania, E-mail: sandra.mikuckyte@ktu.lt \\ **Kaunas University of Technology, Studentu str. 56, 51424, Kaunas, Lithuania, E-mail: vytautas.ostasevicius@ktu.lt \\ cross ${ }^{\text {ref }}$ http://dx.doi.org/10.5755/j01.mech.26.6.25668
}

\section{Introduction}

Intervertebral disc is a sophisticated structure that connects separate vertebras, withstands loads acting on a spinal column and allows its movements. Intervertebral disc consists of gel-like nucleus pulposus surrounded by concentric layers of annulus fibrosus. Superior and inferior surfaces of nucleus pulposus and annulus fibrosus are covered by thin cartilaginous end plates. Most of the nutrients supplied by vertebral capillaries penetrate subchondral plates and enter intervertebral disc through cartilaginous end plates. They diffuse through the end plates and reach cells of nucleus pulposus and annulus fibrosus while metabolites move in opposite direction. Only a small part of nutrients reaches the disc by capillaries of outer layer of annulus fibrosus [1].

The balance between the nutrients supply and consumption is delicate, and its disturbance could reduce activity or viability of the cells which ensure functionality of disc matrix. Nutrition of the cells depends on distance between cells and supply source [2], condition of endplates [3], genetics [4] and other factors. Insufficient nutrition could lead to loss of proteoglycans, dehydration of nucleus pulposus, disorganization and disintegration of annulus fibrosus. This is also known as disc degenerative disease. Due to disc degeneration, height of the disc reduces as well as ability to withstand loads and secure stability of the spinal column and also leads to low back pain $[5,6]$.

Fluid flow within the intervertebral disc is one of the key contributors for control of cell metabolism and could improve transportation of the nutrients. It is known that fluid content in intervertebral disc varies during the day. Height of the disc reduces during day activities and reaches its primary value during night rest as fluid flows out of the disc mostly due to mechanical loading and fluid flows back to the disc due to diffusion which depends on osmotic pressure [7]. Modelling of diurnal cycle loading (16 hours of compressive loading and 8 hours of rest) shows that fluid flow velocity due to daily activities does not increase transportation of low weight solutes (molecular weight of $400 \mathrm{Da}$ ), for example, oxygen, glucose and lactic acid, but enhances transportation of large solutes (molecular weight of $40 \mathrm{kDa}$ ) [8]. Application of compressive $1000 \mathrm{~N} 1 \mathrm{~Hz}$ frequency cyclic load to poroelastic model of spinal functional unit induces fluid flow through the intervertebral disc into the vertebras with fluid flow velocity consistently decreasing due to the reason that less fluid is left in the disc. After the load is removed, fluid starts to flow into the disc, but time is needed for fluid flow velocity to increase [9]. Authors of this study also conclude that disc response to loading depends on loading frequency.
While cell-based therapies to increase fluid flow to and from the intervertebral disc are researched and presented [10], exercise therapy is still the most often used to improve condition of the intervertebral disc and spine in general. Review of animal model researches shows that relationship between loading type and regenerative response of intervertebral disc may exist and while high loading at high volumes and frequencies could start degenerative processes high loading at low volumes and frequencies could induce regenerative processes, for example, to increase fluid flow within the intervertebral disc [11]. Diffusion through the endplates may be increased by forced convection induced by compression-traction loading in healthy and degenerated discs of rabbit models [12].

Moderate intensity running is proven to reduce height and volume of intervertebral discs in thoracic and lumbar regions [13]. Authors of this study discuss that decreased content of fluid in the discs may reduce their load absorption capabilities, cyclic changes of intradiscal pressure are necessary to ensure diffusion and convection of nutrients and metabolites. In vivo study of young healthy adults [14] reveals that runners have better hydrated intervertebral discs with higher glycosaminoglycan levels and the hydration is higher in nucleus region than in other regions.

Also, it is proven that sedentary lifestyle decreases health of intervertebral discs. Results of in vivo magnetic resonance imaging study by Arun et al. [15] show that sustained compressive spinal loading of 4.5 hours in supine position reduces small solute transport rates in intervertebral disc. MRI measurement of fluid content and flow show that sedentary lifestyle (daily sedentary time greater than $67 \%$ of awake time) leads to significantly lower apparent diffusion coefficient, in other words, reduced fluid flow velocity [16].

To sum up, specific exercise regimes should be chosen to improve fluid flow, but only tension-compression loads are more researched in this regard. The purpose of this study is to investigate an influence of basic spine moves (flexion, extension, lateral bending and axial rotation) on fluid flow velocity of intervertebral disc.

\section{Methods}

Intervertebral disc may be considered as poroelastic body with fluid diffusion through the solid porous medium. Relationship between total stress, strain and fluid pore pressure is then written as:

$$
\sigma=C \varepsilon-\alpha_{B} p_{f} I
$$


where: $\sigma$ is Cauchy stress tensor; $C$ is elasticity matrix under drained conditions; $\varepsilon$ is strain; $\alpha_{B}$ is Biot-Willis coefficient; $p_{f}$ is fluid pore pressure and $I$ is the tensor identity.

Calculation of fluid flow within the intervertebral disc is based on Darcy's generalized law:

$$
q=-\frac{\kappa}{\mu} \nabla p
$$

where: $q$ is fluid flux; $\kappa$ is permeability of porous medium; $\mu$ is dynamic viscosity and $\nabla p$ is pressure gradient vector.

Tissues permeability is considered isotropic and strain-dependent:

$$
\kappa=\kappa_{0}\left(\frac{e 1-e_{0}}{e_{0} 1+e}\right)^{2} \exp \left(M\left(\frac{1+e}{1+e_{0}}-1\right)\right)
$$

where: $\kappa_{0}$ is initial permeability; $e_{0}$ is initial voids ratio and $M$ is empirical constant. Voids ratio $e$ is defined as:

$$
e=\frac{\phi}{1-\phi}
$$

where: $\phi$ is tissue porosity and depends on volumetric strain.

Intervertebral disc swelling was simulated by applying osmotic pressure gradient:

$$
\Delta \pi=\varphi_{i} R T \sqrt{c_{F}^{2}+4 \frac{\gamma_{e}^{2}}{\gamma_{i}^{2}} c_{e}^{2}-2 \varphi_{e} R T c_{e}}
$$

where: $\varphi_{i}$ and $\varphi_{e}$ are internal and external osmotic coefficients; $R$ is universal gas constant; $T$ is absolute temperature; $c_{F}$ is fixed charge density; $\gamma_{i}$ and $\gamma_{e}$ are activity coefficients and $c_{e}$ is external salt concentration.

Geometry of lumbar intervertebral disc L4-L5 model (Fig. 1) consists of nucleus pulposus, annulus fibrosus and thin cartilaginous end plates. Composite behaviour of annulus fibrosus is represented by annulus fibrosus matrix and seven layers of annulus fibers. Annulus fibers are modelled as tension-only elements (elastic modulus $E=100 \mathrm{MPa}$; Poisson ratio $v=0.33$; cross-sectional area $A=0.07 \mathrm{~mm}^{2}$ ) with an inclination angle of $\pm 66^{\circ}$. Other material properties of the disc are given in Table 1.

Physical properties used in the model: fluid density $\rho=1000 \mathrm{~kg} / \mathrm{m}^{3}$; fluid viscosity $\mu=1 \cdot 10^{-3} \mathrm{~Pa} \cdot \mathrm{s}$; internal and external osmotic coefficients $\varphi_{i}=0.83, \varphi_{e}=0.92$; universal gas constant $R=8.3145 \mathrm{~J} / \mathrm{mol} \cdot \mathrm{K}$; external salt concentration $c_{e}=150 \mathrm{~mol} / \mathrm{m}^{3}$; initial fluid volume fraction of nucleus pulposus and annulus fibrosus $n_{0_{-} n p}=0.8, n_{0_{-} a f}=0.7$; initial fixed charge density of nucleus pulposus and annulus fibrosus $c_{f 0_{-} n p}=300 \mathrm{~mol} / \mathrm{m}^{3}, c_{f 0_{-} a f}=180 \mathrm{~mol} / \mathrm{m}^{3}$. Drained density of nucleus pulposus and anulus fibrosus $\rho_{d_{-} n p}=\rho_{d_{-} a f}=1040 \mathrm{~kg} / \mathrm{m}^{3}$; drained density of cartilaginous endplates $\rho_{d_{-} \text {cep }}=2500 \mathrm{~kg} / \mathrm{m}^{3}$; Biot-Willis coefficient $\alpha_{B}=1$ and compressibility $4 \cdot 10^{-10} 1 / \mathrm{Pa}$.

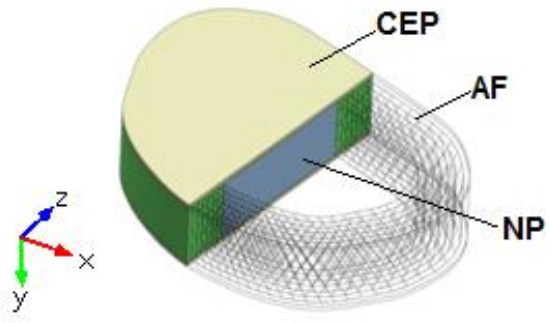

Fig. 1 Geometry of L4-L5 intervertebral disc model: NP nucleus pulposus, AF - annulus fibrosus, CEP - cartilaginous end plates

Model was validated by calculating decrease of disc height to due to static compression. Calculated value of $1.24 \mathrm{~mm}$ is between the presented values of experimental studies. Second part of validation was to check if height of the disc comes back to the initial value after compression is removed. After 16 hours of loading, 8 hours of removed load was enough to reach primary value of disc height.

During simulation, inferior surface of the lower end plate was constrained, and flexion, extension, lateral bending or axial rotation moment was applied to superior surface of the upper end plate. Loading time was set for 2 seconds, with moment increasing to the maximal value of $7.5 \mathrm{Nm}$ during the $1^{\text {st }}$ second and remaining constant for the $2^{\text {nd }}$ second (Fig. 2).

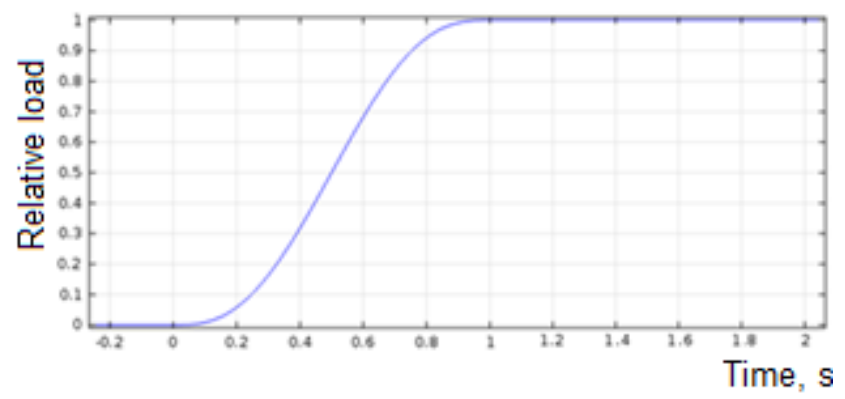

Fig. 2 Intervertebral disc loading curve

Table 1

Material properties of intervertebral disc used in finite element analysis (Material properties are set according to Maladrino et al. [17]; Natarajan et al. [18]; Ferguson et al. [8]; or assumed)

\begin{tabular}{|l|l|l|l|l|l|}
\hline $\begin{array}{l}\text { Spinal } \\
\text { compo- } \\
\text { nent }\end{array}$ & $\begin{array}{l}\text { Elastic } \\
\text { modu- } \\
\text { lus, } \mathrm{MPa}\end{array}$ & $\begin{array}{l}\text { Pois- } \\
\text { son ra- } \\
\text { tio }\end{array}$ & $\begin{array}{l}\text { Initial } \\
\text { poros- } \\
\text { ity }\end{array}$ & $\begin{array}{l}\text { Initial } \\
\text { permea- } \\
\text { bility, } \\
\mathrm{mm} / \mathrm{Ns}\end{array}$ & $\begin{array}{l}\text { Coef- } \\
\text { ficient } \\
M\end{array}$ \\
\hline $\begin{array}{l}\text { Annulus } \\
\text { fibrosus }\end{array}$ & 2.5 & 0.17 & 0.75 & $7.5 \cdot 10^{-16}$ & 8.5 \\
\hline $\begin{array}{l}\text { Nucleus } \\
\text { Pulposus }\end{array}$ & 1 & 0.17 & 0.83 & $7.5 \cdot 10^{-16}$ & 8.5 \\
\hline End plates & 5 & 0.17 & 0.80 & $7.5 \cdot 10^{-15}$ & 8.5 \\
\hline
\end{tabular}

\section{Results}

Average fluid flow velocity of intervertebral disc as well as separate parts of nucleus pulposus, annulus fibrosus and cartilaginous endplates due to flexion, extension, lateral bending and axial rotation was calculated. Initial fluid flow velocity values are not equal to zero due to applied osmotic pressure gradient which is used to simulate 
the swelling of intervertebral disc. Average fluid flow velocity within the disc is the highest due to flexion and extension (Fig. 3) when maximal values of $0.0943 \mu \mathrm{m} / \mathrm{s}$ and $0.0944 \mu \mathrm{m} / \mathrm{s}$ respectively are reached at time step $t=0.8 \mathrm{~s}$. Maximal value of average fluid flow velocity due to lateral bending is $0.066 \mu \mathrm{m} / \mathrm{s}$. Axial rotation leads to the lowest maximal average fluid flow velocity of $0.031 \mu \mathrm{m} / \mathrm{s}$. Shape of the curves representing changes of average fluid flow velocity during two seconds of loading is similar in all four loading cases: maximal average velocity values are reached at $0.8 \mathrm{~s}$ of loading and start to decrease afterwards, although the load remains constant during the $2^{\text {nd }}$ second of loading. This may be explained by reduced fluid content in the disc. Rate of decrease of average fluid flow velocity during the $2^{\text {nd }}$ second of loading is the highest $(30.31 \%)$ when lateral bending moment is applied and the lowest due to axial rotation $(21.38 \%)$. Other values of velocity decrease rate are given in Table 2 .

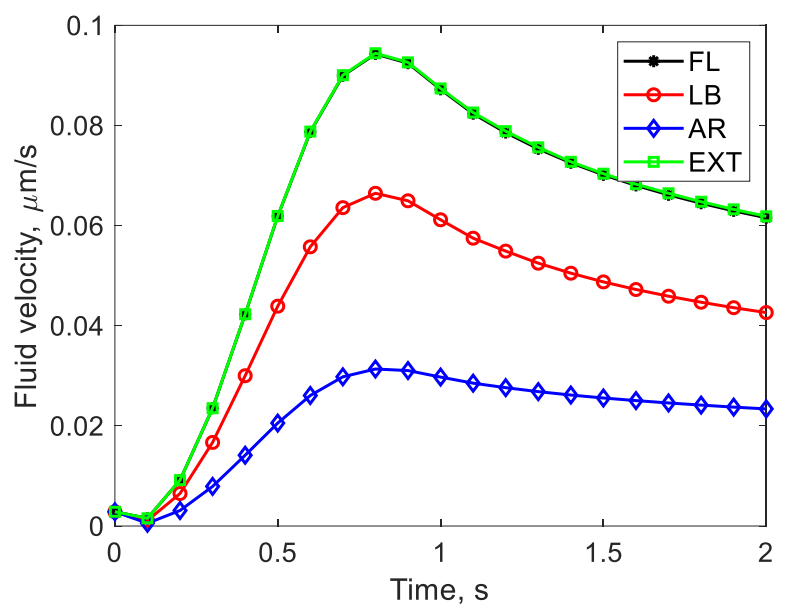

Fig. 3 Average intervertebral disc fluid flow velocity during loadings of 7.5 Nm (FL - flexion, LB - lateral bending, $\mathrm{AR}$ - axial rotation and EXT - extension)

Average fluid flow velocities in nucleus pulposus (Fig. 4), annulus fibrosus (Fig. 5) and cartilaginous end plates (Fig. 6) follows the same tendency when analyzed separately: reach maximal value at $0.8-0.9 \mathrm{~s}$ after loading begins and then start to decrease. In all parts of intervertebral disc, the highest maximal average fluid flow velocity values are induced by flexion and extensions and the lowest ones by axial rotation. Average fluid flow velocity is the highest in cartilaginous end plates (peak value is $0.520 \mu \mathrm{m} / \mathrm{s}$ due to flexion and extension, $0.377 \mu \mathrm{m} / \mathrm{s}$ due to lateral bending and $0.203 \mu \mathrm{m} / \mathrm{s}$ due to axial rotation). Average fluid flow velocity is the lowest in nucleus pulposus (peak value is $0.019 \mu \mathrm{m} / \mathrm{s}$ due to flexion and extension, $0.013 \mu \mathrm{m} / \mathrm{s}$ due to lateral bending and $0.005 \mu \mathrm{m} / \mathrm{s}$ due to axial rotation). Rate of fluid flow velocity decrease during the $2^{\text {nd }}$ second of loading in nucleus pulposus is the highest when axial rotation moment is applied to the intervertebral disc, in annulus fibrosus when extension moment is applied to the disc and in end plates when lateral bending moment is applied to the disc (Table 2).

Average fluid flow velocity component Y (in direction coinciding with vertical axis of spinal column, also shown in Fig. 1) of intervertebral disc as well as separate parts of nucleus pulposus, annulus fibrosus and cartilaginous endplates due to flexion, extension, lateral bending and axial rotation was also calculated. Velocity component $\mathrm{Y}$ is distinguished because it coincides with the most direct path for nutrients to reach middle part of annulus fibrosus and nucleus pulposus. Calculated negative average velocity values represent velocity in opposite direction than default $\mathrm{Y}$ direction.

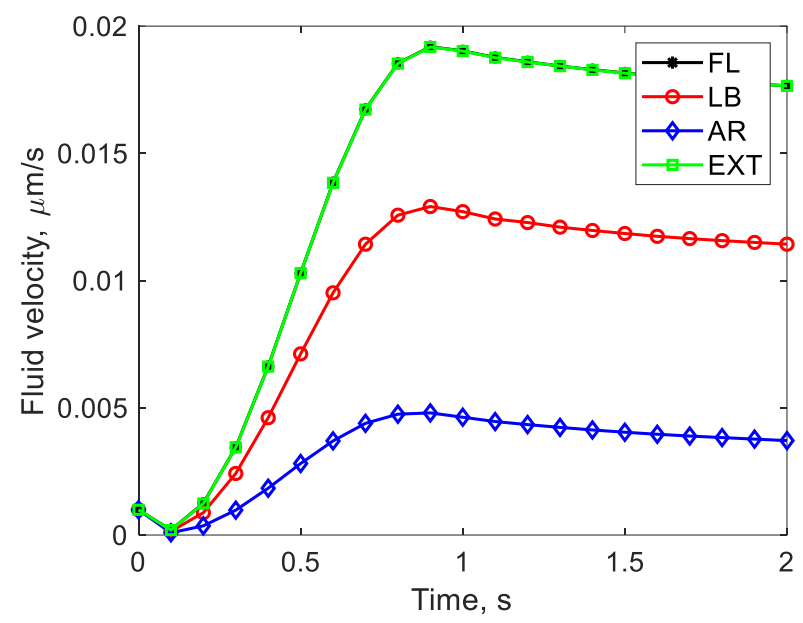

Fig. 4 Average fluid flow velocity in nucleus pulposus during pure loadings of 7.5 Nm (FL - flexion, LB - lateral bending, AR - axial rotation and EXT - extension)

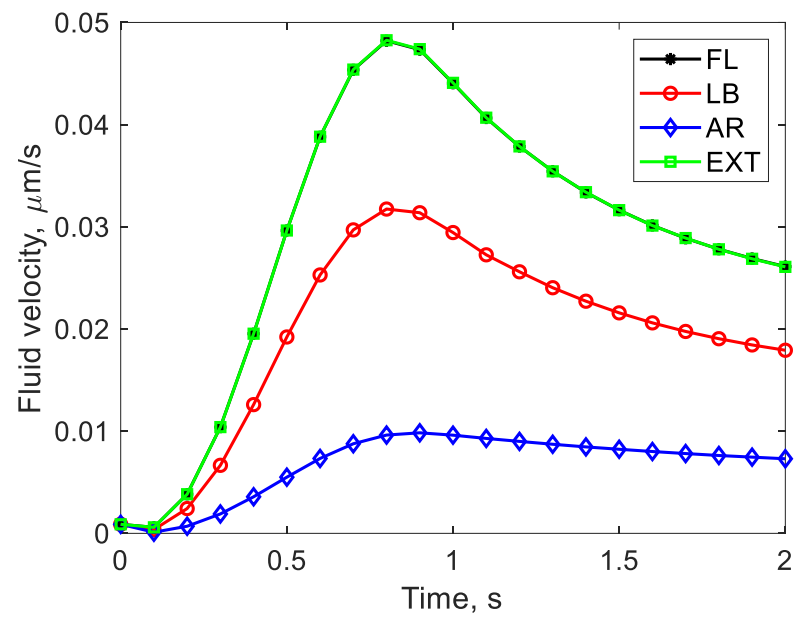

Fig. 5 Average fluid flow velocity in annulus fibrosus during loadings of 7.5 Nm (FL - flexion, LB - lateral bending, AR - axial rotation and EXT - extension)

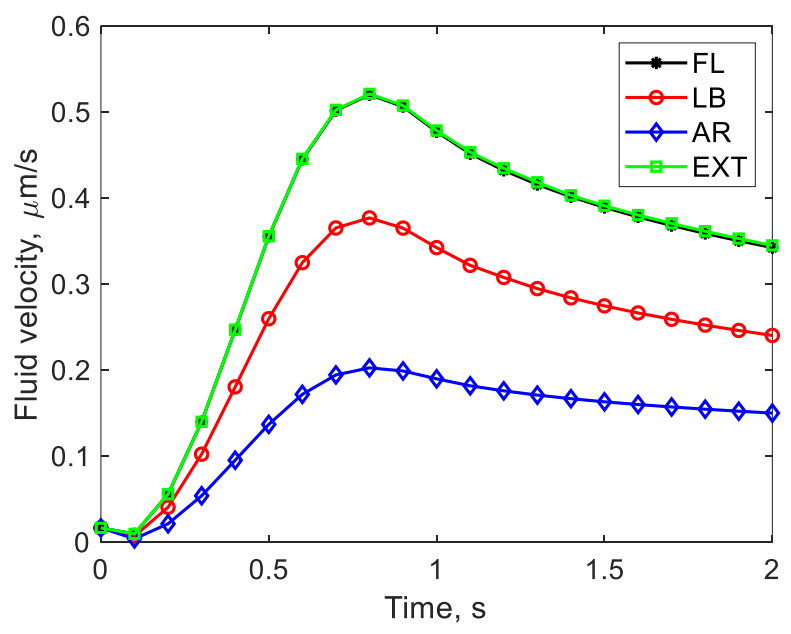

Fig. 6 Average fluid flow velocity in cartilaginous endplates during loadings of 7.5 Nm (FL - flexion, LB - lateral bending, AR - axial rotation and EXT - extension) 
Table 2

Decrease of average fluid flow velocity during the $2^{\text {nd }}$ second of loading

\begin{tabular}{|l|c|c|c|c|}
\hline & Flexion & $\begin{array}{c}\text { Lateral } \\
\text { bending }\end{array}$ & $\begin{array}{c}\text { Axial } \\
\text { rotation }\end{array}$ & Extension \\
\hline Disc & $29.41 \%$ & $30.31 \%$ & $21.38 \%$ & $29.23 \%$ \\
\hline NP & $7.25 \%$ & $10.07 \%$ & $19.87 \%$ & $7.20 \%$ \\
\hline AF & $40.73 \%$ & $39.13 \%$ & $24.04 \%$ & $40.85 \%$ \\
\hline CEP & $28.23 \%$ & $29.81 \%$ & $20.99 \%$ & $27.92 \%$ \\
\hline
\end{tabular}

Average fluid flow velocity in vertical direction of the whole disc is also the highest due to flexion and extension but, in this case, the curves of velocity changes are different (Fig. 7). Maximal average value of fluid velocity component $\mathrm{Y}$ due to flexion is $-1.746 \cdot 10^{-4} \mu \mathrm{m} / \mathrm{s}$ and it is reached at the time step $t=0.8 \mathrm{~s}$. After that moment, it starts to decrease, then reaches and fluctuates about initial value. Average value of fluid velocity component Y due to extension reaches maximal value $\left(2.338 \cdot 10^{-4} \mu \mathrm{m} / \mathrm{s}\right)$ only at time step $t=1.8 \mathrm{~s}$ and then start to decrease. Maximal average value of fluid velocity component $\mathrm{Y}$ due to latera bending is $5.312 \cdot 10^{-5} \mu \mathrm{m} / \mathrm{s}$ and it is reached at the time step $t=0.7 \mathrm{~s}$. Average velocity component $\mathrm{Y}$ due to lateral bending has the similar changing curve as the total average velocity due to the same loading. Changes of average fluid flow velocity component $\mathrm{Y}$ due to axial loading is the least significant with maximal values being $-3.705 \cdot 10^{-5} \mu \mathrm{m} / \mathrm{s}$.

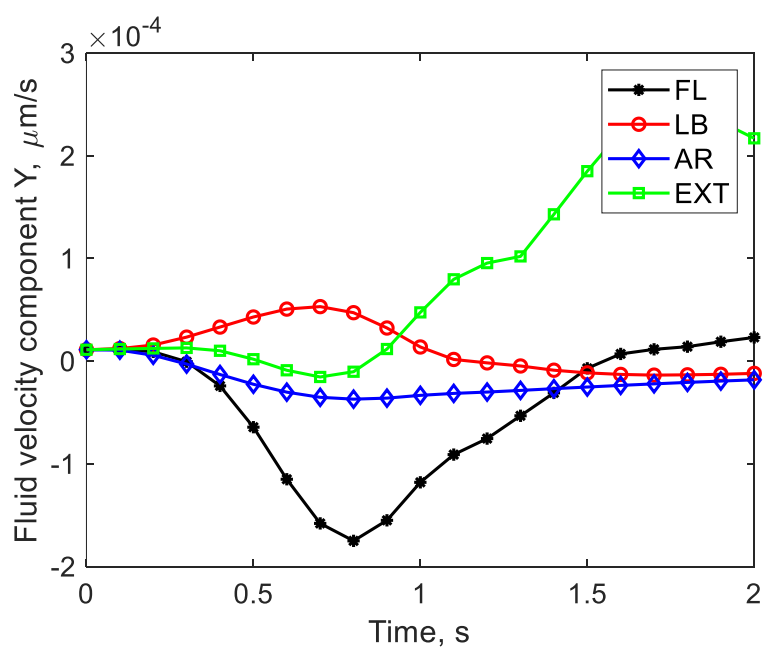

Fig. 7 Average intervertebral disc fluid flow velocity in vertical direction during loadings of 7.5 Nm (FL - flexion, LB - lateral bending, AR - axial rotation and EXT - extension)

Average fluid flow velocity component $\mathrm{Y}$ in nucleus pulposus (Fig. 8) reaches maximal value at time step $t=0.7 \mathrm{~s}$ due to flexion $\left(3.244 \cdot 10^{-6} \mu \mathrm{m} / \mathrm{s}\right)$ and lateral bending $\left(8.37 \cdot 10^{-6} \mu \mathrm{m} / \mathrm{s}\right)$ and then starts to decrease. Component $\mathrm{Y}$ due to extension reaches maximal value of $6.152 \cdot 10^{-6} \mu \mathrm{m} / \mathrm{s}$ at the time step $t=0.6 \mathrm{~s}$, then starts to decrease, reaches initial value and starts to increase again. These fluctuations may be explained as influence of disc swelling due to osmotic pressure. As average fluid flow velocity component $\mathrm{Y}$ values in nucleus pulposus are very small, flow component induced by applied osmotic pressure also reflects in Fig. 8, for example, velocity component $Y$, when axial rotation moment is applied, just slightly decrease from its initial value.

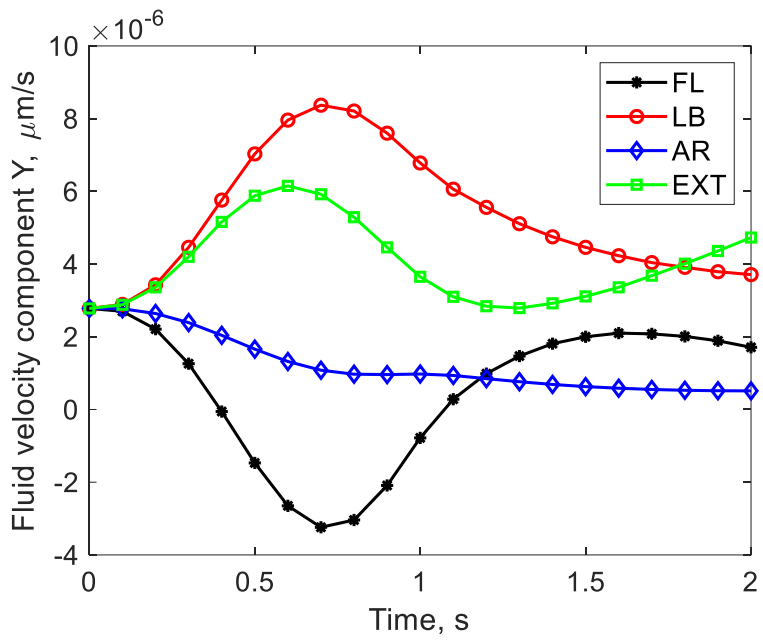

Fig. 8 Average fluid flow velocity in vertical direction in nucleus pulposus during loadings of $7.5 \mathrm{Nm}$ (FL flexion, $\mathrm{LB}$ - lateral bending, $\mathrm{AR}$ - axial rotation and EXT - extension)

Average fluid flow velocity component $\mathrm{Y}$ in annulus fibrosus (Fig. 9) is the highest when flexion moment is applied, then maximal value of $-4.063 \cdot 10^{-5} \mu \mathrm{m} / \mathrm{s}$ is reached at time step $t=0.9 \mathrm{~s}$.

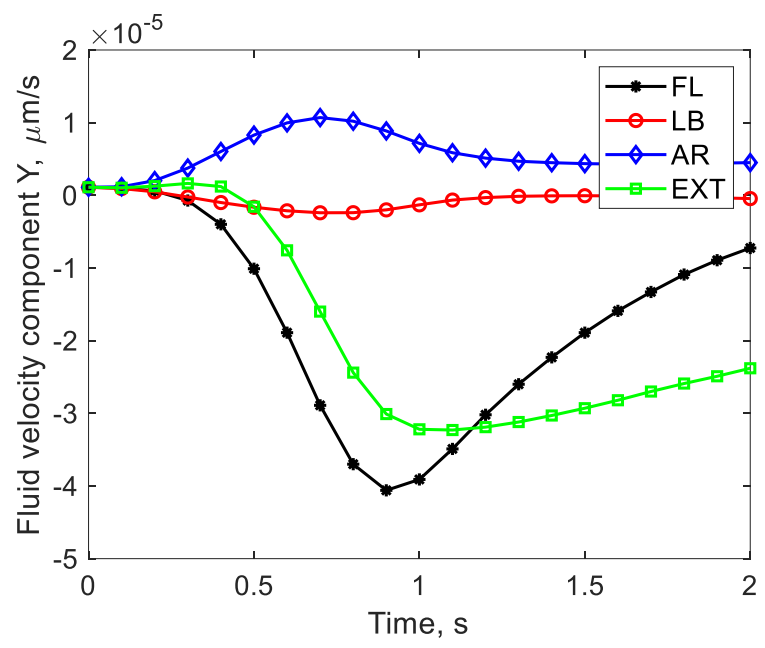

Fig. 9 Average fluid flow velocity in vertical direction in annulus fibrosus during loadings of 7.5 Nm (FL - flexion, LB - lateral bending, AR - axial rotation and EXT - extension)

Maximal value of average component $\mathrm{Y}$ in annulus fibrosus due to extension is $3.234 \cdot 10^{-5} \mu \mathrm{m} / \mathrm{s}$ and is reached at time step $t=1.1 \mathrm{~s}$. After reaching peak value, average velocity component $\mathrm{Y}$ decreases faster due to flexion than extension. Maximal average velocity component $Y$ due to axial rotation is $2.404 \cdot 10^{-5} \mu \mathrm{m} / \mathrm{s}$ and lateral bending has the least significant influence on average velocity component $\mathrm{Y}$ in annulus fibrosus.

Average fluid flow velocity component $\mathrm{Y}$ in cartilaginous end plates (Fig. 10) has almost the same shape of velocity curves as those of average velocity component $\mathrm{Y}$ of the whole disc because component $Y$ values are the highest in the end plates and contribute the most to the average velocity of the whole disk. 


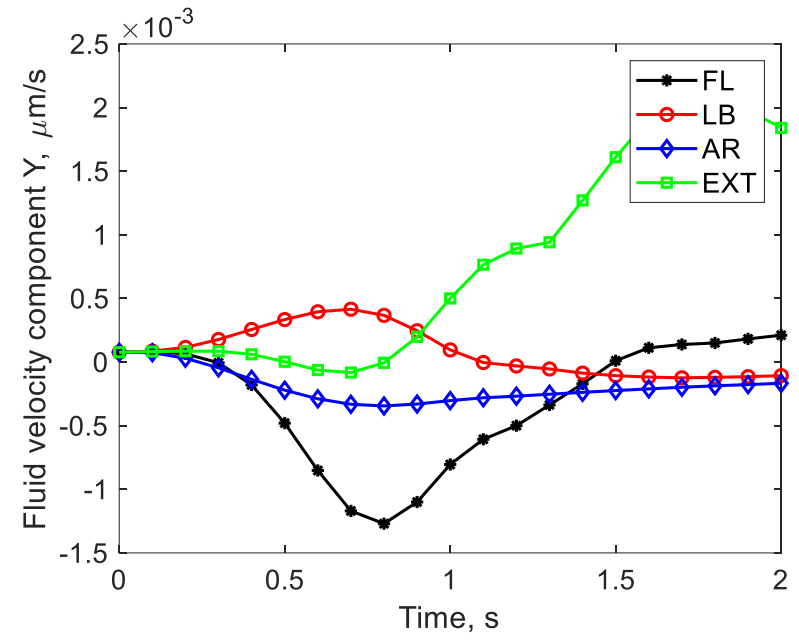

Fig. 10 Average fluid flow velocity in vertical direction in cartilaginous endplates during loadings of $7.5 \mathrm{Nm}$ (FL - flexion, LB - lateral bending, AR - axial rotation and EXT - extension)

\section{Discussion}

Sufficient fluid flow through the intervertebral disc is important for nutrition of the disc. It is proven than convection induced by mechanical loading may increase fluid flow velocity, but compression-traction cyclic loads are researched more than other loading cases. This is the reason why the influence of flexion, common move in daily activities, as well as extension, lateral bending and axial rotation moments on fluid flow velocity within the intervertebral disc was researched in this study.

Average instead of maximal values of flow velocity were chosen in order to eliminate some high velocity values at the most deformed zones or edges of the model. Due to this reason presented velocity values are lower than those usually presented in the literature. Flexion and extension moments induce the highest average total velocity values in all three parts of intervertebral disc. But if only the velocity vector in direction which coincides with axis of spinal column or, in other words, which is the most direct direction for nutrients to reach middle part of the disc is analyzed, lateral bending induces the highest velocity. On the other hand, the values of velocity component $\mathrm{Y}$ are up to hundreds of times smaller than total velocity values in nucleus pulposus, so the assumption that lateral bending moves may be more useful for the health of intervertebral disc cannot sufficiently substantiated only by this data.

Current model does not include vertebral bodies and ligaments that may have some influence on how loading moments are distributed within the disc and this may be considered as a limitation of this study. The further investigation would be necessary to evaluate the influence of already existing disc degeneration processes on fluid flow velocity within the intervertebral disc and this could be the base for creating individual exercise programmes for improvement of spinal health.

\section{Conclusions}

To sum up, poroelastic finite element model of lumbar intervertebral disc is used to calculate fluid flow ve- locity with the intervertebral disc. When comparing the average of flow velocity, the highest values are calculated when flexion and extension moments were applied to the disc, but lateral bending induces the highest value of velocity component in $\mathrm{Y}$ direction in nucleus pulposus, yet the assumption that lateral bending could be more beneficial in order to improve nutrients supply to intervertebral disc cannot be substantiated only by this data, as calculated values of velocity component $\mathrm{Y}$ are significantly lower that total velocity values.

\section{References}

1. Huang, Y. C.; Urban, J. P. G.; Luk, K. D. K. 2014. Intervertebral disc regeneration: do nutrients lead the way? Nature Reviews Rheumatology 10(9): 561-566. https://dx.doi.org/10.1038/nrrheum.2014.91.

2. Maladrino, A.; Noailly, J.; Lacroix, D. 2014. Numerical exploration of the combined effect of nutrient supply, tissue condition and deformation in the intervertebral disc, Journal of Biomechanics 47(6): 1520-1525. https://dx.doi.org/10.1016/j.jbiomech.2014.02.004.

3. Shirazi-Adl, A.; Taheri, M.; Urban, J. P. 2010. Analysis of cell viability in intervertebral disc: Effect of endplate permeability on cell population, Journal of Biomechanics 43(7): 1330-1336.

https://dx.doi.org/10.1016/j.jbiomech.2010.01.023.

4. Feng, Y.; Egan, B.; Wang, J. 2016. Genetic factors in intervertebral disc degeneration, Genes \& Diseases 3: 178-185. https://dx.doi.org/10.1016/j.gendis.2016.04.005.

5. Livshits, G.; Popham, M.; Malkin, I.; Sambrook, P. N.; MacGregor, A. J; Spector, T.; Williams, F. M. K. 2011. Lumbar disc degeneration and genetic factors are the main risk factors for low back pain in women: the UK Twin Spine Study, Annals of the Rheumatic Diseases 70(10): 1740-1745.

https://dx.doi.org/10.1136/ard.2010.137836.

6. Zheng, C. J.; Chen, J. 2015. Disc degeneration implies low back pain, Theoretical Biology and Medical Modelling 12(24): 1-10. https://dx.doi.org/10.1186/s12976-015-0020-3.

7. Bezci, S. E.; O'Connell, G. 2018. Osmotic Pressure Alters Time-dependent Recovery Behavior of the Intervertebral Disc, Spine 43(6): 334-340.

https://dx.doi.org/10.1097/BRS.0000000000002354.

8. Ferguson, S. J.; Ito, K; Nolte, L. P. 2003. Fluid flow and convective transport of solutes within the intervertebral disc, Journal of Biomechanics 37(2): 213-221. https://dx.doi.org/10.1016/S0021-9290(03)00250-1.

9. Guo, L. X; Li, R. 2019. Influence of vibration frequency variation on poroelastic response of intervertebral disc of lumbar spine, Journal of Mechanical Science and Technology 33(2): 973-979. https://dx.doi.org/10.1007/s12206-019-0154-z.

10. Chuang, S. Y.; Popovich, J. M.; Lin, L. C.; Hedman, T. P. 2010. The Effects of Exogenous Crosslinking on Hydration and Fluid Flow in the Intervertebral Disc Subjected to Compressive Creep Loading and Unloading, Spine 35(24): 1362-1366. https://dx.doi.org/10.1097/BRS.0b013e3181e68695. 
11. Steele, J.; Bruce-Low, S.; Smith, D.; Osborne, N; Thorkeldsen, A. 2015. Can specific loading through exercise impart healing or regeneration? The Spine Journal 15: 2117-2121.

https://dx.doi.org/10.1016/j.spinee.2014.08.446.

12. Gullbrand, S. E.; Peterson, J.; Ahlborn, J.; Mastropolo, R.; Fricker, A.; Roberts, T. T.; Abousayed, M.; Lawrence, J. P.; Glennon, J. C., Ledet, E. H. 2015. Dynamic Loading-Induced Convective Transport Enhances Intervertebral Disc Nutrition, Spine 40(15): 1158 - 1164. https://dx.doi.org/10.1097/BRS.0000000000001012.

13. Kingsley, M. I.; D'Silva, L. A.; Jennings, C.; Humphries, B.; Dalbo, V. J.; Scanlan, A. T. 2012. Moderate-intensity running causes intervertebral disc compression in young adults, Medicine \& Science in Sports \& Exercise 44(11): 2199-2204. https://dx.doi.org/10.1249/MSS.0b013e318260dbc1.

14. Belavy, D.L.; Quittner, M. J.; Ridgers, N.; Ling, Y.; Connel, D.; Rantalainen, T. 2017. Running exercise strengthens the intervertebral disc, Scientific Reports 7. https://dx.doi.org/10.1038/srep45975.

15. Arun, R.; Freeman, B. J. C; Scammell, B. E; McNally, D. S; Cox, E.; Gowland, P. 2009. What influence does sustained mechanical load have on diffusion in the human intervertebral disc?: an in vivo study using serial postcontrast magnetic resonance imaging, Spine 34(21): 2324-2337. https://dx.doi.org/10.1097/BRS.0b013e3181b4df92.

16. Bowden, J. A.; Bowden, A. E.; Wang, H.; Hager, R. L.; LeCheminant, J. D.; Mitchell, U. H. 2018. In Vivo Correlates Between Daily Physical Activity and Intervertebral Disc Health, Journal of Orthopaedic Research 36(5):1313-1323. https://dx.doi.org/10.1002/jor.23765.

17. Maladrino, A.; Planell, J. A.; Lacroix, D. 2009. Statistical factorial analysis on the poroelastic material properties sensitivity of the lumbar intervertebral disc under compression, flexion and axial rotation, Journal of Biomechanics 42: 2780-2788. https://dx.doi.org/10.1016/j.jbiomech.2009.07.039.

18. Natarajan, R. N.; Williams, J. R.; Andersson, G. B. J. 2006. Modeling changes in intervertebral disc mechanics with degeneration, The Journal of Bone \& Joint Surgery $88(2)$ : 36-40.

https://dx.doi.org/10.2106/JBJS.F.00002.

\section{S. Mikuckytè, V. Ostaševičius}

\section{INVESTIGATION OF FLUID FLOW VELOCITY WITHIN THE INTERVERTEBRAL DISC}

\section{S u m m a r y}

Enhancing fluid flow velocity within the intervertebral disc may allow to increase solute transportation rates and improve disc nutrition as the sufficient supply of the nutrients to cells of intervertebral disc is a key factor in order to avoid or delay processes of disc degeneration. Poroelastic finite element model of lumbar intervertebral disc is used to calculate fluid flow velocity with the intervertebral disc due to flexion, extension, lateral bending and axial rotation. When comparing the average of flow velocity, the highest values are calculated when flexion and extension moments were applied to the disc, but lateral bending induces the highest value of velocity component in Y direction in nucleus pulposus, yet the assumption that lateral bending could be more beneficial in order to improve nutrients supply to intervertebral disc cannot be substantiated only by this data, as calculated values of velocity component $\mathrm{Y}$ are significantly lower that total velocity values.

Keywords: Intervertebral disc, fluid flow velocity, poroelastic model.

Received April 07, 2020

Accepted December 01, 2020

This article is an Open Access article distributed under the terms and conditions of the Creative Commons Attribution 4.0 (CC BY 4.0) License (http://creativecommons.org/licenses/by/4.0/). 